\title{
Reply to Comment on: "Women Could Avoid Axillary Lymph Node Dissection by Choosing Breast-Conserving Therapy Instead of Mastectomy"
}

\author{
Armando E. Giuliano, $\mathrm{MD}^{1}$, and Marissa Vane, $\mathrm{MD}^{2,3}$ \\ ${ }^{1}$ Department of Surgery, Cedars-Sinai Medical Center, Los Angeles, CA; ${ }^{2}$ Department of Surgery, Maastricht University \\ Medical Center+, Maastricht, The Netherlands; ${ }^{3}$ GROW - School for Oncology and Developmental Biology, Maastricht \\ University Medical Center+, Maastricht, The Netherlands
}

\section{TO THE EDITORS:}

We greatly appreciate the comments made by Drs. Cortina and Kong from the Medical College of Wisconsin. ${ }^{1}$ It was not our intent to diminish the findings of the AMAROS trial nor its impact on the surgical management of the axilla in mastectomy patients; however, it is true that not many mastectomy patients were included in the AMAROS trial. More importantly, nearly all of our patients have immediate reconstruction. We are reluctant to use post-mastectomy radiotherapy in patients in whom a tumor-involved sentinel node was removed during mastectomy with immediate reconstruction. These patients may have limited nodal disease and have no other indication for post-mastectomy radiotherapy. The adverse effects of chest wall irradiation on the reconstructed breast are well known. Irradiation may not be necessary for all patients with a sentinel node metastasis. We do at times use post-mastectomy radiotherapy for patients with positive sentinel nodes rather than return to the operating room but prefer to understand the extent of disease in order to avoid unnecessary damage to a reconstructed breast.

\section{REFERENCES}

1. Cortina CS, Kong AL. Comment on: "Women could avoid axillary lymph node dissection by choosing breast-conserving therapy instead of mastectomy”. Ann Surg Oncol. 2021. https://doi.org/10. 1245/s10434-021-09931-x.

Publisher's Note Springer Nature remains neutral with regard to jurisdictional claims in published maps and institutional affiliations.

(C) Society of Surgical Oncology 2021

First Received: 18 March 2021

Accepted: 18 March 2021;

Published Online: 23 April 2021

A. E. Giuliano, MD

e-mail: armando.giuliano@cshs.org 